
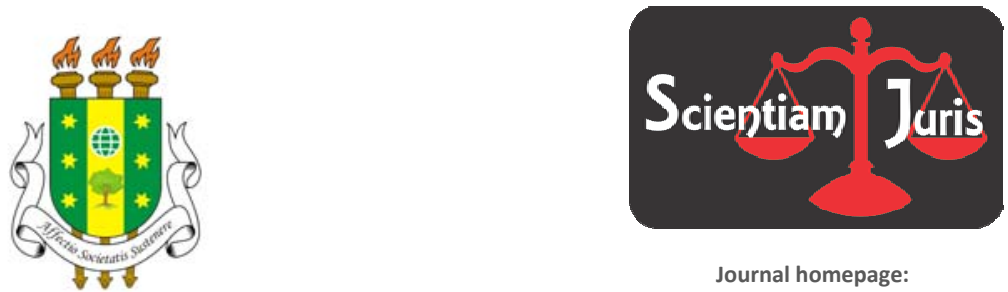

Journal homepage:

www.arvore.org.br/seer

\title{
PRESCRIÇÃO VIRTUAL À LUZ DO PRINCÍPIO DA DIGNIDADE DA PESSOA HUMANA
}

\section{RESUMO}

Este artigo buscou três objetivos. O primeiro deles foi entender a prescrição virtual, denominada também como prescrição penal antecipada, reconhecimento antecipada da prescrição penal, prescrição em perspectiva, prognose prescricional, prescrição precalculada ou projetada, à luz do panorama doutrinário e exemplificativo acerca do tema, a fim de fundamentar a aplicabilidade dessa nova modalidade prescricional. O segundo objetivo consistiu na compreensão do princípio constitucional da dignidade da pessoa humana dentro de um contexto histórico e valorativo, que norteia as relações intersubjetivas e as estabelecidas entre o Estado e os administrados, irradiando seus efeitos para todo o ordenamento jurídico. Por último, objetivou-se apontar a dignidade da pessoa humana - valor fundamental do sistema normativo - como respaldo jurídico do instituto prescricional em comento, ressaltando as implicações de um processo penal inócuo e inútil, afastado do propósito do Direito Penal e do que preceitua o Estado Democrático de Direito, na vida privada do réu. Diante disso, pode-se vislumbrar a aplicabilidade do tema em face da preservação da dignidade da pessoa humana.

PALAVRAS-CHAVE: Jus Puniendi; Prescrição Penal; Prescrição Virtual; Princípio da Dignidade da Pessoa Humana; Estado Democrático de Direito.

\section{PRESCRIPTION VIRTUAL AND CONSIDERATIONS OF THE HUMAN DIGNITY}

\section{ABSTRACT}

This article has three objectives. The first was to understand the virtual limitation also termed as criminal prescription early, early recognition of the limitation law, limitation in perspective, prognosis statute, prescription or precalculada designed in light of the panorama of doctrine and examples on the subject in order to support the applicability of this new way of limitation. The second objective was to understand the constitutional principle of human dignity within a historical context and value, governing the relationship between them and those established between the state and administered by radiating effects for the entire legal system. Finally, the aim is to show the dignity of the individual- a fundamental value of the regulatory systemsuch as legal support of the institute statute under discussion, highlighting the implications of criminal proceedings innocuous and useless, far from the purpose of criminal law and stipulates that the Democratic State of Law, in the privacy of the defendant. Thus, one may envisage the applicability of the subject in view of the preservation of human dignity.

KEYWORDS: Jus Puniendi; Prescription Criminal; Prescription Virtual; Principle of Human Dignity; Democratic State of Law.

Scientiam Juris, Aquidabã, v.1, n.1, Set, Out, Nov, Dez 2012, Jan, Fev 2013.

\section{ISSN 2318-3039}

\section{SECTION: Articles}

TOPIC: Direito Penal e Processo Penal

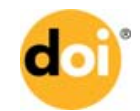

DOI: 10.6008/ESS2318-3039.2013.001.0005

Magna Oliveira Pires de Santana

Centro Universitário Jorge Amado, Brasil http://lattes.cnpq.br/9692768436360591 magna pires@hotmail.com

Received: $12 / 06 / 2012$

Approved: 15/02/2013

Reviewed anonymously in the process of blind peer.

\section{Referencing this:}

SANTANA, M. O. P.. Prescrição virtual à luz do princípio da dignidade da pessoa humana. Scientiam Juris, Aquidabã, v.1, n.1, p.46-56, 2013. DOI: http://dx.doi.org/10.6008/ESS23183039.2013.001.0005 


\section{INTRODUÇÃO}

A prescrição penal é vislumbrada como impedimento ao exercício do ius puniendi estatal, já que se constitui em causa extintiva da punibilidade, pois o Estado não exerceu a pretensão punitiva ou a pretensão executória no lapso temporal determinado.

Nesse contexto, com vistas à efetividade do processo penal e a sua racional pretensão punitiva em face ao princípio da dignidade da pessoa humana, dirigidas ao objetivo do Direito Penal, o presente artigo trata de um tema recente e polêmico, que gera debate no mundo jurídico relacionado à prescrição penal, cujo conteúdo é trazido sob o título de Prescrição Virtual à Luz do Princípio da Dignidade da Pessoa Humana.

O artigo tem por objeto o estudo da prescrição virtual e as vantagens da sua aplicabilidade no mundo jurídico, tornando o processo humano, eficaz e útil.

\section{METODOLOGIA}

A pesquisa empreendida teve três momentos. No primeiro momento, foi realizado um levantamento bibliográfico acerca do tema tratado, já que o assunto é recente e polêmico quanto à sua aplicabilidade. Numa fase posterior, analisou-se o princípio constitucional da dignidade da pessoa humana como norteador do sistema jurídico vigente. Por fim, fez-se uma demonstração da operacionalização do aludido instituto prescricional à luz do princípio da dignidade da pessoa humana.

\section{DISCUSSÃO TEÓRICA}

\section{Prescrição Virtual}

O tema é polêmico, despertando debates acirrados na doutrina e dividindo a jurisprudência, por ser recente e não haver previsão legal pátria. A prescrição virtual apresenta diversas denominações, como prescrição penal antecipada, reconhecimento antecipada da prescrição penal, prescrição em perspectiva, prognose prescricional, prescrição precalculada ou projetada.

Baltazar (2003, p.107) conceitua a prescrição virtual como:

[...] o reconhecimento da prescrição retroativa, antes da sentença, com base na pena a que o réu seria condenado, evitando assim, o desperdício de tempo na apuração de coisa nenhuma, pois já se sabe, antecipadamente, que o resultado será a extinção da punibilidade.

Capez (2007, p.568-569) ensina que:

a prescrição da pretensão punitiva virtual, perspectiva, projetada ou antecipada é a prescrição reconhecida antecipadamente, em geral ainda na fase extrajudicial, com base na provável pena concreta, que será fixada pelo juiz, no momento futuro 
da condenação.

Conforme Lozano Jr. (2002, p.181), a prescrição virtual:

[...] consiste no reconhecimento da prescrição retroativa antes mesmo do oferecimento da denúncia ou da queixa e, no curso do processo, anteriormente à prolação da sentença, sob o raciocínio de que eventual pena a ser aplicada em caso de hipotética condenação traria a lume um prazo prescricional já decorrido.

$\mathrm{Na}$ lição de Palotti Jr. (1994, p.302-306), a prescrição virtual constitui "[...] 0 reconhecimento da prescrição retroativa, tomando-se por base a pena que possível ou provavelmente seria imposta ao réu no caso de condenação."

Ao observarem - o magistrado, no momento em que receber a inicial acusatória, ou o membro do Ministério Público, diante do inquérito policial ou mesmo da peça de informação, ou ao fazer a denúncia - que as circunstâncias judiciais (art. 59, do CP) e legais (arts. 61 e 65, do CP), acrescidas das condições pessoais do suposto agente da conduta delitiva, como não ser reincidente, ter confessado, são totalmente favoráveis, bem como inexistirem causas de aumento de pena, ocasionando, provavelmente, a fixação concreta da pena em seu mínimo legal, deve-se reconhecer a prescrição virtual, haja vista que uma eventual condenação já estaria fulminada pelo lapso prescricional.

A fim de maior entendimento do conceito, é cabível um exemplo: A foi denunciado pelo crime de resistência simples (art. 329, caput, do CP), que prescreve em 4 (quatro) anos, eis que o máximo da pena privativa de liberdade é estabelecido em 2 (dois) anos, nos termos do art. 109, inc. $\mathrm{V}$, do CP). Diante do processo, o juiz verifica que $\mathbf{A}$ é primário e que tem bons antecedentes, bem como, não existirem agravantes ou causas de aumento. Ademais, observa que já transcorreu o lapso temporal de mais de 2 (dois) anos desde a data da consumação do crime. Dessa forma, o magistrado conclui que a pena in concreto não ultrapassaria o mínimo legal, isto é, 2 (dois) meses. Como essa pena de 2 (dois) meses prescreve em 2 (dois) anos, conforme art.109, inc. VI, do $\mathrm{CP}$, o mesmo deixa de acolher a acusação, não recebendo a denúncia, para reconhecer a modalidade prescricional em alusão.

Registre-se que, no momento da análise das circunstâncias legais e judiciais, bem como das condições pessoais do acusado, ainda restar duvidosa a possibilidade quanto à aplicação da prescrição virtual, deve o operador do direito impelir o feito adiante, à luz do princípio in dubio pro societate, o qual consiste na decisão em favor da sociedade.

Nessa esteira, o membro do parquet também pode deixar de oferecer a exordial acusatória ou até mesmo requerer o seu reconhecimento, a fim da extinção da punibilidade com todos os seus efeitos, penais e civis, como estabelece o art. 91, inc. I, do Codex. ${ }^{1}$

Cumpre destacar o ensinamento de Machado (1994, p.432-433):

Questão de grande relevo, sobretudo para os que se preocupam com a morosidade do Poder Judiciário, reside em saber se é válido o julgamento antecipado da ação penal. Com efeito, é possível que em

\footnotetext{
1 "Art. 91. São efeitos da condenação:

I- tornar certa a obrigação de indenizar o dano causado pelo crime; [...]"
} 
muitos casos o Juiz, depois de haver recebido a denúncia, reste convencido da improcedência da ação, seja porque o fato não configura crime, mesmo em tese, seja porque inequivocamente já extinta a punibilidade pela prescrição, ou porque, presente outra razão para se dar pela improcedência da denúncia, sejam quais forem as provas que possam vir a ser colhidas na instrução... Sem qualquer apreço pelo formalismo estéril, considero perfeitamente cabível o julgamento antecipado da ação penal, sempre que o julgador estiver convencido da impossibilidade de proferir sentença condenatória, quaisquer que sejam as provas colhidas na instrução. Não se pode perder o Juiz no formalismo, que é, penso eu,a principal causa da morosidade do Poder Judiciário.

\section{O Princípio da Dignidade da Pessoa Humana}

Dentro do panorama histórico da dignidade da pessoa humana, revelam-se duas correntes doutrinárias que contribuíram para a compreensão do seu conteúdo: a tradição cristã e a filosofia Kantiana.

A doutrina cristã revelou a noção de dignidade da pessoa humana para o mundo ocidental. O Cristianismo difundiu a idéia de que o ser humano seria dotado de dignidade, tendo em vista que fora criado à imagem e semelhança de Deus.

Nos séculos XVII e XVIII, a corrente jusnaturalista transformou o fundamento do Direito Natural, o qual passou de Direito divino para Direito racional, sob o prisma da razão humana. Com isso, propagou-se a idéia do ser racional, a partir dos novos contornos trazidos pela racionalização e laicização. Essa mudança foi influenciada, inclusive, pelo lluminismo, pois esta corrente de pensamento desprendeu o homem da religião, pondo-o no centro do universo.

A par disso, Sarlet (2006, p.33) ensina que:

Da concepção jusnaturalista - que vivenciava seu apogeu justamente no século XVIII - remanesce, indubitavelmente, a constatação de que uma ordem constitucional que - de forma direta ou indireta - consagra a idéia da dignidade da pessoa humana, parte do pressuposto de que o homem, em virtude tão-somente de sua condição humana e independentemente de qualquer outra circunstância, é titular de direitos que devem ser reconhecidos e respeitados por seus semelhantes e pelo Estado.

Neste período, aponta-se a doutrina de Immanuel Kant acerca da concepção moderna da dignidade humana. A filosofia Kantiana foi precursora no que concerne ao sentido dado à existência do ser humano como sendo um fim em si mesmo. Defendeu que o homem deveria ser vislumbrado pelo Estado como finalidade e não apenas como meio. Dessa forma, sua obra "Fundamentação da metafísica dos costumes" forneceu limites à atividade estatal e subsídios para fundamentar o conceito da dignidade da pessoa humana.

No século XVIII, sob a inspiração das idéias individualistas ressaltadas na Revolução Francesa, a Declaração dos Direitos do Homem e do Cidadão, de 26 de agosto de 1789, iniciou a discussão acerca da viabilização de um tratamento protetivo aos Direitos Humanos no plano internacional.

O conteúdo da Declaração Universal dos Direitos Humanos, referendada pela Assembléia 
Geral das Nações Unidas, em 10 de dezembro de 1948, foi ratificado após a II Conferência Mundial dos Direitos Humanos em Viena, no ano de 1993, no intuito de realizar a cooperação mútua entre os países integrantes, a fim do combate às desigualdades socioeconômicas, em face de um ideal permeado pela elevação da espécie humana de forma digna.

A proteção da dignidade do homem obteve uma qualificação jurídica a partir da inserção dessa premissa nos textos constitucionais das Nações no período final da Segunda Guerra Mundial, tendo em vista que o pós-guerra gerou a necessidade da reconstrução dos direitos humanos. Nesse contexto, Barcellos (2002, p.108) pontua que:

A reação à barbárie do nazismo e do fascismo em geral levou, no pós-guerra, a consagração da dignidade da pessoa humana no plano internacional e interno como valor máximo dos ordenamentos jurídicos e princípio orientador da atuação estatal e dos organismos internacionais. Diversos países cuidaram de introduzir em suas Constituições a dignidade da pessoa humana como fundamento do Estado [...].

Diante dessa tendência mundial, o legislador constituinte brasileiro de 1998 consolidou o princípio da dignidade da pessoa humana em seu artigo $1^{\circ}{ }^{2}$, constituindo-o em fundamento constitucional.

Esse dispositivo constitucional reflete os preceitos ressaltados pelos Direito Humanos e norteia toda a Constituição da República para que se garanta a defesa e a preservação de uma sobrevivência física com dignidade, sendo imprescindível, para tanto, o desenvolvimento econômico e social qualitativo, visando o bem-estar social.

A dignidade pode ser compreendida como um valor intrínseco, um atributo intangível da pessoa humana, ou seja, insuscetível de reprimendas. À luz da filosofia Kantiana, Camargo (2007, p.118) conclui que "[...] pode-se dizer que a dignidade humana consiste em um atributo resultante da noção de que toda pessoa é um fim em si mesmo e que, por essa razão, não deve ser tratada como mero instrumento ou objeto".

No plano axiológico, a dignidade da pessoa humana é vislumbrada como valor fonte, refletindo, como preceitua a filosofia Kantiana, o próprio existir do ser humano. Esse valor consiste no princípio fundamental do sistema jurídico, sendo visualizado no vértice do ordenamento, a fim de direcionar toda a sua produção normativa.

Sobre o assunto, Sarlet (2006, p.70) verbera que:

Num primeiro momento - convém frisá-lo -, a qualificação da dignidade da pessoa humana como princípio fundamental traduz a certeza de que o artigo $1^{\circ}$, inciso III, de nossa Lei Fundamental não contém apenas (embora também e acima de tudo) uma declaração de conteúdo ético e moral, mas que constitui norma jurídicopositiva dotada, em sua plenitude de status constitucional formal e material e, como tal, inequivocamente carregado de eficácia, alcançando, portanto - tal como sinalou Benda - a condição de valor jurídico fundamental da comunidade. Importa considerar, neste contexto, que, na sua qualidade de princípio e valor fundamental, a dignidade da pessoa humana constitui-se de acordo com a

\footnotetext{
2 "Art. $1^{\circ}$ A República Federativa do Brasil, formada pela união indissolúvel dos Estados e Municípios e do Distrito Federal, constitui-se em Estado Democrático de Direito e tem como fundamentos:

$[\ldots]$

III- a dignidade da pessoa humana; [...]"
} 
preciosa lição de Judith Martins-Costa, autêntico "valor fonte que anima e justifica a própria existência de um ordenamento jurídico", razão pela qual, para muitos, se justifica plenamente sua caracterização como princípio constitucional de maior hierarquia axiológico-valorativa (höchstes wertsetzendes Verfassungsprinzip).

Não se pode conceber a dignidade da pessoa humana desvinculada dos direitos fundamentais, já que as duas noções encontram-se intimamente ligadas e interdependentes. Destarte, da dignidade da pessoa humana decorrem os direitos fundamentais e por meio destes, a dignidade se concretiza.

Nesse sentido, Camargo (2007, p.118) assevera que:

[...] é indiscutível a existência de uma relação de dependência mútua entre a dignidade da pessoa humana e os direitos fundamentais. Ao mesmo tempo em que os direitos fundamentais surgiram como uma exigência da dignidade de proporcionar um pleno desenvolvimento da pessoa humana, é certo também que somente através da existência desses direitos a dignidade poderá ser respeitada, protegida e promovida. Por essa razão, a exigência de cumprimento e promoção dos direitos fundamentais, encontra-se estreitamente vinculada ao respeito à dignidade da pessoa humana.

O princípio constitucional da dignidade da pessoa humana constitui uma cláusula geral para os direitos da personalidade. Diversos direitos fundamentais refletem e complementam a concepção de dignidade da pessoa humana, sendo de suma importância para o livre desenvolvimento da personalidade.

Nesta esteira, Sarlet (2006, p.86) leciona que:

[...] é precipuamente com fundamento no reconhecimento da dignidade da pessoa por nossa Constituição, que se poderá admitir, também entre nós e apesar da omissão do Constituinte neste particular, a consagração - ainda que de modo implícito - de um direito ao livre desenvolvimento da personalidade.

Em relação aos direitos da personalidade, destacam-se - no que diz respeito ao presente estudo - a liberdade, como noção de autonomia da vontade, e a igualdade, significando a própria essência da dignidade, como valores conexos à dignidade e à personalidade.

A par disso, o citado autor pontua, ainda, que:

Para além das conexões já referidas (especialmente no concernente à liberdade pessoal e seus desdobramentos) - situa-se o reconhecimento e proteção da identidade pessoal (no sentido de autonomia e integridade psíquica e intelectual) [...], tudo a revelar a já indicada conexão da dignidade, não apenas com um direito geral ao livre desenvolvimento da personalidade, mas também com os direitos de personalidade em geral (SARLET, 2006, p.86).

No âmbito das derivações da dignidade da pessoa humana, a liberdade revela-se como o direito de autodeterminação, consistindo em um limite à relação entre particular e Estado ou entre particulares. Nesse contexto, Camargo (2007, p.118) dispõe que "Os direitos de liberdade se fundamentam, em toda a sua extensão, na dignidade da pessoa humana. São derivações diretas e nela se sustentam, na medida em que qualquer restrição arbitrária ou desproporcional constitui um atentado à dignidade."

O valor igualdade divide-se em igualdade formal e material. A igualdade formal implica a obrigatoriedade do tratamento igual para os iguais, bem como do tratamento desigual para os 
desiguais, a fim de igualá-los. Dessa forma, funciona - segundo Moraes (2003, p.50) - como impedimento de "tratamentos abusivamente diferenciados a pessoas que encontram-se em situações idênticas."

A igualdade material consiste no elemento central da dignidade da pessoa humana, tendo em vista que compreende o mínimo existencial, que se compõe de direitos básicos, tais como: saúde, educação fundamental, moradia, dentre outros, os quais tornam a vida digna. A respeito disso, Sarlet (2006, p.60) ressalta que o Estado deve se ater ao:

[...] complexo de direitos e deveres fundamentais que assegurem a pessoa contra todo e qualquer ato de cunho degradante e desumano, como venham a the garantir as condições existenciais mínimas para uma vida saudável, além de propiciar e promover sua participação ativa e co-responsável nos destinos da própria existência e da vida em comunhão com os demais seres humanos.

Para tanto, impõe-se a irradiação dos efeitos desse princípio constitucional para todo o ordenamento jurídico, sendo um vetor à produção e à interpretação normativas. Assim, cabe ao Estado o dever de respeito, proteção e promoção de uma vida digna.

Sobre o assunto, cumpre transcrever a doutrina de Camargo (2007, p.121):

The last, but not the least é o dever imposto aos poderes públicos no sentido de respeitá-la, protegê-la e promover os meios necessários ao alcance das condições mínimas indispensáveis a uma vida digna e ao pleno desenvolvimento da personalidade. Nesse prisma, respeitar (observar) significa a não realização de atividades que importem a sua violação ("obrigação de abstenção"); proteger implica uma ação positiva para defendê-la contra qualquer espécie de violação por parte de terceiros; e, promover consiste em proporcionar, por meio de prestações materiais positivas, os meios indispensáveis a uma vida digna.

O Estado Democrático de Direito é entendido por Silva (2007, p.120) como sendo:

[...] um tipo de Estado que tende a realizar a síntese do processo contraditório do mundo contemporâneo, superando o Estado capitalista para configurar um Estado promotor de justiça social que o personalismo e o monismo político das democracias populares sob o influxo do socialismo real não foram capazes de construir.

O Estado Democrático de Direito revela a soberania popular, a qual determina a participação ativa e efetiva do povo sobre a res pública, respaldada no princípio democrático que tutela os direitos fundamentais da pessoa humana.

O princípio da dignidade da pessoa humana norteia o Estado Democrático de Direito, o qual preceitua que o processo deve ser efetivo, adequado e tempestivo, desaguando em um provimento jurisdicional útil à sociedade. Assim, o apego ao formalismo legal constituir-se-ia uma retrocessão ao Estado de Direito clássico, limitado a um conceito de lei.

Sobre o assunto, o mencionado autor leciona que:

[...] a lei não deve ficar numa esfera puramente normativa, não pode ser apenas lei de arbitragem, pois precisa influir na realidade social. E se a Constituição se abre para as transformações políticas, econômicas e sociais que a sociedade brasileira requer, a lei se elevará de importância, na medida em que, sendo fundamental expressão do direito positivo, caracteriza-se como desdobramento necessário do conteúdo da Constituição e aí exerce função transformadora da sociedade, impondo mudanças sociais democráticas, ainda que possa continuar a desempenhar uma função conservadora, garantindo a sobrevivência de valores socialmente aceitos (SILVA, 2007, p.121). 


\section{Princípio da Dignidade da Pessoa Humana como Fundamento Jurídico da Prescrição Virtual}

Conforme a lição de Zaffaroni (2003, p.47), o sistema penal é mantido por meio da seleção vitimizante e a vulnerabilidade das pessoas desvaloradas pela sociedade. Para ele, o Direito Penal subjetivo, ou como denomina, a criminalização secundária seleciona, inevitavelmente, o figurino social dos delinqüentes, sob orientação burocrática.

Dessa forma, o autor sustenta que:

[...] o poder punitivo atinge aqueles que se tornam vulneráveis à criminalização secundária porque: a) suas características pessoais se enquadram nos estereótipos criminais; b) sua educação só Ihes permite realizar ações ilícitas toscas e, por conseguinte, de fácil detecção e c) porque a etiquetagem suscita a assunção do papel correspondente ao estereótipo, com o qual seu comportamento acaba correspondendo ao mesmo (a profecia que se auto-realiza) (ZAFFARONI, 2003, p.48).

Portanto, a aplicação da sanção penal é estigmatizante, no tocante a criar imagem pública do delinquente, associando todas as cargas negativas da sociedade de acordo com os preconceitos em relação à classe social, cor, sexo, componentes étnicos e estéticos, entre outros. Daí porque se verifica uma uniformidade quanto à população penitenciária.

Assim, a criminalização serve como instrumento para a culpabilidade e estigmatização pública, tornando o processo penal um meio transformador do status jurídico-pessoal do acusado.

A exemplo dos efeitos penais transformadores do status pessoal do condenado, Ferrajoli (2002, p.586) pontua:

a) a inscrição da condenação nas certidões judiciais (arts. 685 a 690 do Código de Processo Penal), b) o status de reincidente de delinqüente ou contraventor habitual, profissional ou por tendência (arts. 99-109 do Código Penal), com a conseqüente aplicação das medidas de segurança (art. 215 e ss. do Código Penal) e a inaplicabilidade de anistia, indulto (arts. 151 , par. $5^{\circ}$ e 174 , par. $3^{\circ}$, do Código Penal), c) os efeitos dos antecedentes judiciais para fins de determinação da pena (art. 133, caput, n. 2 do Código Penal); [...]. Em contraste com este interminável elenco de efeitos pós-penais estigmatizantes, aos quais se conjugam as penas acessórias do tipo de interdição, volta-se a mente à disposição IX, formulada há mais de dois séculos por Morelly em seu Code de la nature: ' uma vez cumprida a pena, está proibido a todo cidadão fazer a menor reprovação à pessoa que sofreu ou a seus parentes, de dizer às pessoas que ignorem-no e ainda demonstrar o mínimo desprezo em relação aos culpados, seja na sua presença ou na sua ausência, sob pena de receber a mesma punição que àquele foi dada.

É notória a interferência do processo penal existente na vida privada do réu, vez que causa constrangimento ilegal na vida do mesmo, quando provável o reconhecimento da prescrição virtual. Com efeito, Brandão (1994, p.391-392) afirma que "é evidente o constrangimento a que está sujeito o réu, que aguardará por longos meses seu julgamento para que, mesmo se condenado for, somente então se possa ter a prescrição reconhecida."

Ademais, exige-se que a intervenção do direito de punir estatal seja verificada somente quando necessária, pois:

[...] somente a danosidade social pode-se constituir-se como fundamento para a 
legitimação da punibilidade, e, por conseqüência, onde houver estabilização social como resultado da prática de um fato delituoso alcançado pela prescrição projetada não se justifica a interferência do Direito Penal. Destarte, a tolerabilidade social com um fato ocorrido não pleiteia a resposta do sistema através do processo e da pena (MACHADO, 2000, p.167).

Outrossim, revela-se inútil a continuidade de um processo inócuo, pois será fatalmente fulminado pelo instituto da prescrição. A possibilidade de reconhecimento da prescrição virtual, com isso, demonstra diversas vantagens para a esfera privada do réu. Nesse diapasão, Fernandes (2006, p.38-43) leciona que:

[...] submeter alguém aos dissabores de um processo penal, tendo a certeza de que será inútil, constitui constrangimento ilegal, uma vez que a mesma injustiça, decorrente da acusação posta sem que seja possível antever condenação do réu, existe quando não há possibilidade de cumprimento da sentença condenatória porque será alcançada pela prescrição.

Portanto, há uma correspondência entre a interferência do processo na vida do réu e a carência de ação por falta de interesse de agir. Dessa forma, fundamenta-se que o processo gera constrangimento ilegal, por falta de justa causa, ensejando, ademais, a impetração de habeas corpus, nos termos do art. 648, inc. I, do Código de Processo Penal.

Nesse sentido, a jurisprudência colacionada abaixo:

PRESCRIÇÃO ANTECIPADA. POSSIBILIDADE. O processo, como instrumento, não tem razão de ser, quando o único resultado previsível levará, inevitavelmente, ao reconhecimento da ausência de pretensão punitiva. $O$ interesse de agir exige da ação penal um resultado útil. Se não houver aplicação possível de sanção, inexistirá justa causa para a ação penal. Assim, só há uma concepção teratológica do processo, concebido como autônomo, auto-suficiente e substancial, pode sustentar a indispensabilidade da ação penal, mesmo sabendo-se que levará ao nada jurídico, ao zero social. E à custa de desperdício de tempo e recursos materiais do Estado. Dessa forma, demonstrando que a pena projetada, na hipótese de uma condenação, estaria prescrita, deve-se declarar a prescrição, pois a submissão do acusado ao processo decorre do interesse estatal em proteger o inocente e não intimidá-lo, numa forma de adiantamento de pena. Recurso improvido. ${ }^{3}$ (grifos nossos)

Machado (2000) defende que o direito de punir estatal somente se justifica conforme verificação de uma sentença penal condenatória, porque, caso contrário, estar-se-ia violando os postulados do Estado Democrático de Direito e o princípio da dignidade da pessoa humana. Nesse prisma, verbera que:

[...] pela perda do valor simbólico do fato cometido e de sua conseqüente penalização pelo transcurso do tempo, materializado pelo desaparecimento da necessidade da pena, qualquer processo penal em trâmite ou futura imposição de condenação que não redundará na efetiva aplicação da lei penal constitui-se como atentado à dignidade humana (MACHADO, 2000, p.163).

Dessa forma, o desenvolvimento do processo penal fadado ao insucesso devido à extinção da punibilidade não atende ao princípio da dignidade da pessoa humana, eis que contraria o objetivo da sanção penal, sendo que o processo serviria tão-somente como instrumento de estigmatização social.

\footnotetext{
${ }^{3}$ TJRS - APL 70005159371 - Rel. Sylvio Batista Neto
} 
Assim, resta demonstrada a aplicabilidade do instituto prescricional em tela, tendo em vista que o princípio da dignidade da pessoa humana - centro da normatividade jurídica - deve guiar todo o feito ou processo penal. Com efeito, Silva (2007, p. 95) conclui que "[...] a dignidade da pessoa humana não é uma criação constitucional, pois ela é um desses conceitos a priori, um dado preexistente a toda experiência especulativa, tal como a própria pessoa humana." Por isso, ela "[...] não estará assegurada se o indivíduo é humilhado, discriminado, perseguido ou depreciado" (SILVA, 2007, p.95).

\section{CONSIDERAÇÕES FINAIS}

O presente artigo pretendeu ressaltar os argumentos favoráveis ao tema, no intuito de demonstrar a sua ampla aplicabilidade nos Juízos Criminais, à luz do princípio da dignidade da pessoa humana.

Malgrado o posicionamento majoritário em oposição ao tema, este trabalho científico deságua no entendimento favorável à viabilidade da prescrição virtual, a fim do atendimento ao princípio da dignidade da pessoa humana. Destarte, seriam evitados o desgaste da imagem da justiça, bem como gastos sociais com um processo inócuo.

A par disso, antevendo o reconhecimento da prescrição retroativa na eventualidade de futura condenação e diante das circunstâncias legais e judiciais do caso concreto, deve-se aplicar a prescrição virtual, eis que restou demonstrada a falta de interesse de agir e de justa causa, no intuito de impedimento de uma ação penal inadequada e inútil, a qual configuraria, tão-somente, um constrangimento ilegal, passível de impetração de habeas corpus, consoante art. 648, I, do CPP.

Partindo da constatação de que o processo penal verifica-se como um meio transformador do status jurídico-pessoal do acusado, não se pode admitir que esse processo possa ser inútil e ineficaz. Com isso, o princípio da dignidade da pessoa humana fundamenta a modalidade prescricional em comento, no sentido do atendimento à consecução do interesse estatal, porque, ao contrário, estar-se-ia submetendo o acusado, tão-somente, aos dissabores do processo penal, sancionando-o - de antemão - diante dessa interferência na sua vida privada.

Assim, o apego ao formalismo legal e o receio quanto ao novo, externados pela corrente doutrinária contrária ao tema, atentam contra o princípio da dignidade da pessoa humana, uma vez que o desenrolar do feito penal inócuo submete o réu tão-somente à estigmatização social sem atingir seu resultado útil. Ademais, obstam o progresso jurídico e a prática de soluções que apontem para a celeridade processual e para aos valores ressaltados no Estado Democrático de Direito.

\section{REFERÊNCIAS}

BALTAZAR, A. L.. Prescrição penal: prescrição da pretensão punitiva; retroativa; intercorrente; antecipada; 
da pretensão executória; da pena de multa; das penas restritivas de direito; direito comparado. Bauru: EDIPRO, 2003.

BARCELLOS, A. P.. A eficácia jurídica dos princípios constitucionais: o princípio da dignidade da pessoa humana. Rio de Janeiro: Renovar, 2002.

BRANDÃO, E. A.. Prescrição em perspectiva. Revista dos Tribunais, São Paulo, n.710, p.391-392, 1994.

CAMARGO, M. N.. O conteúdo jurídico da dignidade da pessoa humana. In: CAMARGO, M. N.. Leituras complementares de constitucional: direitos fundamentais. 2 ed. Salvador: Juspodivm, 2007.

CAPEZ, F.. Curso de direito penal: parte geral. São Paulo: Saraiva, 2007.

FERNANDES, A. S.. A provável prescrição retroativa e a falta de justa causa para a ação penal. Cadernos de Doutrina e Jurisprudência da Associação Paulista do Ministério Público, n.6, p.38-43, 2006.

FERRAJOLI, L.. Direito e razão: teoria do garantismo penal. São Paulo: Revista dos Tribunais, 2002.

LOZANO JR., J. J.. Prescrição penal. São Paulo: Saraiva, 2002.

MACHADO, F. G. P.. Prescrição penal: prescrição funcionalista. São Paulo: Revista dos Tribunais, 2000.

MACHADO, H. B.. Julgamento antecipado em matéria penal. Revista dos Tribunais, n.707, p.432-433, 1994.

MORAES, A.. Direito constitucional. 13 ed. São Paulo: Atlas, 2003.

PALOTTI JR., O.. Considerações sobre a prescrição retroativa antecipada. Revista dos Tribunais, n.709, p.302-306, 1994.

SARLET, I. W.. Dignidade da pessoa humana e direitos fundamentais na Constituição Federal de 1988. 2 ed. Porto Alegre: Livraria do Advogado, 2006.

SILVA, J. A.. Curso de direito constitucional positivo. 28 ed. São Paulo: Malheiros, 2007.

ZAFFARONI, E. R.. Direito penal brasileiro. 2 ed. Rio de Janeiro: Revan, 2003. 